\title{
A Rational Expectations Model of Financial Contagion
}

\author{
Laura E. Kodres \\ and \\ Matthew Pritsker* \\ This Version: April 19, 2001 \\ Forthcoming in the Journal of Finance
}

\begin{abstract}
We develop a multiple asset rational expectations model of asset prices to explain financial market contagion. Although the model allows contagion through several channels, our focus is on contagion through cross-market rebalancing. Through this channel, investors transmit idiosyncratic shocks from one market to others by adjusting their portfolios' exposures to shared macroeconomic risks. The pattern and severity of financial contagion depends on markets' sensitivities to shared macroeconomic risk factors, and on the amount of information asymmetry in each market. The model can generate contagion in the absence of news, and between markets that do not directly share macroeconomic risks.
\end{abstract}

*International Monetary Fund and the Board of Governors of the Federal Reserve System, respectively. The authors thank Sriram Rajan for research assistance, and Mico Loretan for useful comments and extensive guidance in preparing this document. Comments from audiences and discussants at the Federal Reserve Board, the Bank of Japan, the Federal Reserve Bank of Atlanta Financial Markets Conference, the International Monetary Fund, the National Bureau of Economics Research Summer Institute, the Washington Area Finance Conference, the University of Maryland, Georgetown University, Rutgers University, and Vanderbilt University are gratefully acknowledged. The views expressed in this paper are those of the authors but not necessarily those of the International Monetary Fund or the Board of Governors of the Federal Reserve System. 


\section{Introduction}

A spate of recent financial crises - the Mexican crisis of 1995, the Asian crisis of 1997-98, the default of the Russian government in August 1998, the sharp depreciation of the real in Brazil in 1999 - have been accompanied by episodes of financial markets contagion in which many countries have experienced increases in the volatility and comovement of their financial asset markets on a day-to-day basis. The pattern of contagion has been uneven across both time and countries - with increased volatility and comovement occurring principally during times of financial and exchange rate crises - and with some countries, particularly those with emerging financial markets, having experienced the bulk of the contagion, while countries with more developed markets have remained relatively unscathed.

Although heightened financial market volatility is to be expected within countries experiencing financial and exchange rate crises, the pattern of comovement across countries is not easily explained. Some of the increased comovement among countries that compete through trade or share close economic links can be rationalized on the basis of macroeconomic theory; but these theories are less persuasive in accounting for the increased comovement among the financial markets of weakly linked countries such as those of South East Asia and Latin America. An alternative reason for the increased comovement is that financial markets are responding to the same public news events. However, even accounting for the release of economic news and other information, much of the increased volatility and comovement across countries remains unexplained (Kaminsky and Schmukler, 1999; Baig and Goldfajn, 1999; Connolly and Wang, 2000).

In this paper we present a rational expectations model of financial markets. The model is designed to describe asset price movements over short periods of time- such as a day or a week - during which macroeconomic conditions can be taken as given. Using the model we provide an explanation for the cross-sectional and time-series pattern of financial market contagion. In particular we show why emerging markets are especially vulnerable to contagion and why contagion is more likely to appear during times of financial and exchange rate 
crises. Our model also illustrates how contagion can occur in the absence of public news, and between countries that do not directly share common macroeconomic fundamentals.

Our paper is related to the burgeoning literature on contagion. One branch of this literature emphasizes contagious currency crises, relating such crises to various monetary and financial sector vulnerabilities, including financial market imperfections, incomplete contracting, or weaknesses in government policy. These studies often look for the underlying causes behind a simultaneous set of speculative attacks. ${ }^{1}$ A second branch emphasizes contagion spreading as a result of linkages among financial institutions, ${ }^{2}$ while a third branch focuses on contagion among financial markets.

Our paper is most closely related to studies of contagion among financial markets. These papers have principally focused on contagion through a correlated information or a correlated liquidity shock channel. Under the correlated information channel, price changes in one market are perceived as having implications for the values of assets in other markets, causing their prices to change as well (King and Wadhwani, 1990). The correlated liquidity shock channel posits that when some market participants need to liquidate some of their assets to obtain cash, perhaps due to a call for additional collateral, they choose to liquidate assets in a number of markets, effectively transmitting the shock (Calvo, 1999 and Yuan, 2000).

Neither of these channels can completely account for the cross-sectional pattern of contagion. The correlated information channel assumption that price changes in one market have implications for asset values in other markets is plausible for closely linked markets, but it seems less reasonable when applied to Latin America and Asia. The correlated liquidity shock channel is not wholly satisfying for a different reason. Market participants, when hit with a liquidity shock, would benefit most from selling in highly liquid markets since this lowers the impact of their sell orders on prices. This means participants, given a choice-when

\footnotetext{
${ }^{1}$ The financial fragilities associated with contagion are analyzed in Corsetti, Pesenti, and Roubini (1999), Rigobon (1998), Agénor and Aizenman (1998), Goldfajn and Valdés (1997), Caballero and Krishnamurthy (1999), Chan-Lau and Chen (1998), Kaminsky and Reinhart (2000) and others.

${ }^{2}$ Allen and Gale (2000) and Lagunoff and Schreft (2001) provide analyses of contagion caused by linkages among financial intermediaries. Van Rijckeghem and Weder (2000) empirically document such linkages.
} 
hit with a liquidity shock — would liquidate positions in developed not emerging markets. ${ }^{3}$ Under this scenario, the fact that contagion has primarily affected a large cross-section of emerging markets cannot be explained by liquidity shocks alone.

The general model of contagion that we present in the next section is an extension of the static, single risky asset, noisy rational expectations model of Grossman and Stiglitz (1980), GS hereafter, to a multiple asset setting. The GS model was first extended to a multipleasset setting by Admati (1985) and has since been extended in a number of directions by others. ${ }^{4}$ We have stayed close to GS's original framework to highlight our ideas in as simple a setting as possible. The main innovation is the economic interpretation that we give to elements of the GS model. In our model, each risky asset is the national stock market index of a separate country. The liquidation value of each market index is decomposed into a component which represents some investors' private information about that country and into a residual component which is driven by macroeconomic factors. This decomposition provides insight into how the macroeconomic risk factor structure of the economy and the amounts of information asymmetry in different countries together interact to determine the pattern of financial market contagion.

Our theoretical model nests a number of formal channels for contagion including the correlated information and correlated liquidity shock channels discussed above. Because our model is tractable (even with a large number of markets) it can be used to study the properties of the contagion channels proposed by others. In a recent paper, Kyle and Xiong (2001) present a model in which contagion only occurs through wealth effects. Because our model does not contain wealth effects, we view their approach as complementary.

\footnotetext{
${ }^{3}$ However, if some money managers are only permitted to take positions in emerging markets and are forced to liquidate their holdings the impact could be concentrated predominately in emerging markets, rather than transferred to the more liquid developed markets. Moveover, there may be instances where portfolio risk management rules require liquidation in the most risky markets, not necessarily those with the most liquidity (Schinasi and Smith (2000)).

${ }^{4}$ Admati (1985) considers a continuum of investors that have diverse private information. Others have extended the model to a dynamic setting with either a single risky asset (Wang, 1993 and 1994) or with multiple risky assets (Zhou, 1998, and Brennan and Cao, 1997). A recent extension by Yuan (2000) introduces borrowing constraints on the informed investors in a static, single-risky asset setting.
} 
Although we believe other channels may be important for contagion, in most of our analysis here, we concentrate on a variant of the model that only allows for contagion through a new channel that we refer to as cross-market rebalancing. ${ }^{5}$ In the cross-market rebalancing variant of our model investors respond to shocks in one market by optimally readjusting their portfolios in other markets, transmitting the shocks, and generating contagion. When portfolio rebalancing occurs in markets with information asymmetries, the resulting price movements are exaggerated because the orderflow is misconstrued as being informationbased. We believe that the cross-market rebalancing channel has been overlooked in previous studies and provides a richer explanation of financial market contagion.

We define contagion in our model quite generally as a price movement in one market resulting from a shock in another market. While this definition is broad, we show that the price movements resulting from contagion in the cross-market rebalancing variant of our model are excessive relative to full information fundamentals. Thus, the model generates price changes that are consistent with the more traditional notions of contagion. However, despite the connotation that the contagion is "irrational," the contagious price movements generated by our model occur in a framework in which all market participants are rational.

The next section presents our general model of asset prices. The properties of the model for contagion are explored in sections II through V. Section VI relates the properties of the model to the patterns of contagion in recent crises. Section VII concludes.

\section{The General Model}

Our model of asset prices is a two period endowment economy. The economy contains N risky assets with fixed net supply $X_{T}$, and a riskless asset (the numeraire) which is in perfectly elastic supply and has a gross rate of return normalized to 1. Investors trade the assets of the economy in the first period, and then consume the liquidation value of all assets in the

\footnotetext{
${ }^{5}$ Fleming, Kirby, and Ostdiek (1998) used the cross-market rebalancing channel as motivation for their empirical study of volatility comovement. They did not, however, develop a theoretical model.
} 
second period. The prices at which trades take place in the first period is denoted by the $N \times 1$ vector $P$. The liquidation value of the assets at time 2 is represented by the random vector $v$.

\section{A Market Participants}

There are three types of participants in the model, informed investors, uninformed investors, and noise traders (also often referred to as liquidity traders). Informed investors have superior information relative to other investors about the liquidation value of the assets. They receive information on the liquidation value of the assets before trading takes place at time 1 . Their information can be represented by decomposing the liquidation value of the assets into two components, $\theta$ and $u$ :

$$
v=\theta+u
$$

The first component, $\theta$, represents the expected value of $v$ conditional on the information of the informed investors. Throughout the paper we refer to $\theta$ as the information of the informed investors. The second component, $u$, is a residual which represents that component of $v$ which is not explained by the information. Because $u$ is a residual, its mean is assumed to be 0 and it is uncorrelated with $\theta$. The unconditional joint distribution of $\theta$ and $u$ is assumed to be normal with probability distribution

$$
\left(\begin{array}{l}
\theta \\
u
\end{array}\right) \sim \mathcal{N}\left[\left(\begin{array}{l}
\bar{\theta} \\
0
\end{array}\right),\left(\begin{array}{cc}
\Sigma_{\theta} & 0 \\
0 & \Sigma_{u}
\end{array}\right)\right]
$$

Investors in the model are assumed to behave competitively in the sense that they take prices as given. The number of informed investors is $\mu_{I}$ and the number of uninformed investors is $\mu_{U I}$. Both types of investors choose their portfolio positions at time 1 to maximize the expected utility of consuming their time 2 wealth, $W_{2}$. Informed investors know the 
realization of $\theta$, and use this information in their portfolio choices. Each informed investor has CARA utility with risk tolerance parameter $\tau$, and time 1 wealth $W_{1}$. Borrowing and lending take place without constraint at the riskless rate of interest, which is normalized to 0 . This allows each informed trader to choose his positions in the risky assets, $X_{I}(P, \theta)$, to maximize:

$$
\begin{gathered}
E\left[-\exp \left(-W_{2} / \tau\right) \mid \theta\right] \\
\text { subject to } W_{2}=W_{1}+X_{I}^{\prime}(v-P) .
\end{gathered}
$$

It is well known that the optimal choice of $X_{I}(P, \theta)$ satisfies:

$$
\begin{aligned}
X_{I}(P, \theta) & =\tau \operatorname{Var}(v \mid \theta)^{-1}(\mathrm{E}(v \mid \theta)-P) \\
& =\tau \Sigma_{u}^{-1}(\theta-P),
\end{aligned}
$$

where $\operatorname{Var}(v \mid \theta)=\Sigma_{u}$ and $\mathrm{E}(v \mid \theta)=\theta$. Uninformed investors have the same utility function as informed investors but choose their portfolio positions without knowledge of $\theta$. They do, however, know the structure of the model including the unconditional distribution of $\theta$ and $u$ from equation (2). They also observe $P$ (which reveals information about the value of $\theta$ ) and condition their choices on $P$. In particular, the uninformed choose $X_{U I}(P)$ (the subscript "UI" denotes "uninformed"), their positions in the risky assets to maximize

$$
\begin{gathered}
\mathrm{E}\left[-\exp \left(-W_{2} / \tau\right) \mid P\right] \\
\text { subject to } W_{2}=W_{1}+X_{U I}^{\prime}(v-P) \text {. }
\end{gathered}
$$

It is well known that the optimal $X_{U I}(P)$ satisfies:

$$
X_{U I}(P)=\tau \operatorname{Var}(v \mid P)^{-1}(\mathrm{E}(v \mid P)-P) .
$$


The optimal $X_{U I}(P)$ depends on $\operatorname{Var}(v \mid P)$ and $\mathrm{E}(v \mid P)$, and both of these depend on the informativeness of $P$ for $v$. These belief functions and $P$ need to be solved together as part of the overall general equilibrium of the model.

The third type of participants are noise traders. Unlike the first two types of participants whose demands depend on traders' assessment of fundamental value, $v$, noise traders buy and sell assets based on their own idiosyncratic need for liquidity. The demands of noise traders are assumed to be uncorrelated with other participants' objectives, and uncorrelated with the fundamental value of the assets. The presence of noise traders in our model prevents equilibrium prices from fully revealing the information of the informed investors. The net demand of noise traders is denoted by $\epsilon$, which has the distribution

$$
\epsilon \sim \mathcal{N}\left(0, \Sigma_{\epsilon}\right)
$$

\section{B Equilibrium and the Information about $v$ Revealed by $P$}

In this section we solve for the competitive rational expectations general equilibrium price function for the economy. A competitive rational expectations equilibrium exists in period 1 provided that prices $P$ are set so that markets clear, agents are price takers and their demands maximize their utility, and agents equilibrium beliefs about fundamentals are consistent with the information about fundamentals that is revealed by prices. We use the market clearing and belief consistency condition to solve for equilibrium prices and beliefs following a threestep procedure. First, we substitute the utility maximizing demands from equations (4), (6), and (7) into the market clearing condition to solve for the information revealed by $P$ given equilibrium beliefs. Next, we solve for the equilibrium beliefs that are consistent with the information revealed by equilibrium prices. Finally, given the information revealed by $P$, we solve for the equilibrium price function.

Market clearing requires that prices are set so that supply equals demand. This requires 
that prices $P$ and beliefs $\mathrm{E}(v \mid P)$ and $\operatorname{Var}(v \mid P)$ satisfy the equation

$$
\begin{aligned}
X_{T} & =\mu_{U I} X_{U I}(P)+\mu_{I} X_{I}(\theta, P)+\epsilon \\
& =\mu_{U I} \tau \operatorname{Var}(v \mid P)^{-1}(\mathrm{E}(v \mid P)-P)+\mu_{I} \tau \Sigma_{u}^{-1}(\theta-P)+\epsilon .
\end{aligned}
$$

Recall that we assume that uninformed investors know the structure of the model. By this we mean that they know: the parameters of the demand for assets by the other two types of investors given in equations (4) and (7); the unconditional distribution of $\theta$ and $u$ given in equation (2); and prices, $P$. However, they do not know the realization of $\theta$ and $\epsilon$. Given this information structure, equation (8) can be arranged so that everything known by uninformed investors is summarized by $S(P)$, which can be written as $\theta$ plus a function of noise traders' demands. In other words, knowledge of $S(P)$ provides uninformed investors with a noisy signal of $\theta$, the information of the informed investors:

$$
S(P)=\theta+\frac{\Sigma_{u} \epsilon}{\tau \mu_{I}}
$$

where

$$
S(P)=\frac{-1}{\tau \mu_{I}} \Sigma_{u}\left[\mu_{U I} \tau \operatorname{Var}(v \mid P)^{-1}(\mathrm{E}(v \mid P)-P)-\mu_{I} \tau \Sigma_{u}^{-1} P-X_{T}\right] .
$$

Equation (9) summarizes the information that is revealed by prices to uninformed investors given their beliefs and knowledge of the economic structure. To make the beliefs consistent with the information revealed by prices we require that beliefs satisfy the consistency conditions

$$
\begin{aligned}
\mathrm{E}(v \mid P) & =\mathrm{E}[v \mid S(P)] \\
\text { and } \quad \operatorname{Var}(v \mid P) & =\operatorname{Var}[v \mid S(P)] .
\end{aligned}
$$


Imposing these consistency conditions, while exploiting the joint normality of $S(P), \theta$ and $\epsilon$, we solve for $\mathrm{E}(v \mid P)$ as a function of $\theta$ and $\epsilon$, and we solve for $\operatorname{Var}(v \mid P)$. It is important to emphasize that our expressions for $\mathrm{E}(v \mid P)$ and $\operatorname{Var}(v \mid P)$ are not explicit functions of equilibrium prices, but are instead consistency conditions on beliefs that must be satisfied by the equilibrium price function. Equilibrium price functions are found by rewriting the market clearing condition, equation (8), while substituting in our expressions for $\mathrm{E}(v \mid P)$ and $\operatorname{Var}(v \mid P)$. We also solve for the unconditional variance-covariance matrix of prices. Our closed-form expression for price is provided in the following proposition:

Proposition 1 The rational expectations equilibrium price function $P$ for the model described by equations (1),(2),(4),(6), and (7) is

$$
P=M_{0}+M_{1} \mathrm{E}(v \mid P)+M_{2} \theta+M_{3} \epsilon
$$

Proof: See the appendix.

This expression for the equilibrium price allows us to characterize how shocks which affect some assets spread to others. This is analyzed in detail in the next section of the paper.

\section{Contagion in the General Model}

In this section, we derive the channels for contagion that are present in our model. Because the specification of the assets has been general up to this point, the model can be used to explain how shocks to one asset or class of assets spread to others. For our purposes, we interpret each risky asset as representing the portfolio of assets that trade in a particular asset market, and then use the model to explain contagion between markets. Contagion occurs when a shock in one market affects prices in other markets. The model contains two types of shocks, which we refer to as information shocks and liquidity shocks. Information shocks are the information learned by informed investors, represented by the realizations of 
$\theta$. Liquidity shocks are the trades made by noise traders due to their idiosyncratic needs for liquidity, represented by the realizations of $\epsilon$. To examine how contagion occurs in our model, we begin by examining the effects that both types of shocks have on prices in general, and then discuss the circumstances under which the shocks are transmitted across markets.

The relationship between asset prices and various shocks is based on the closed form expression for $P$, equation (13). Differentiating $P$ with respect to $\epsilon$ and $\theta$, respectively, the change in price due to liquidity shocks (noise trading) is

$$
\frac{\partial P}{\partial \epsilon}=M_{1} \frac{\partial \mathrm{E}(v \mid P)}{\partial \epsilon}+M_{3},
$$

and the change in price due to information shocks is

$$
\frac{\partial P}{\partial \theta}=M_{1} \frac{\partial \mathrm{E}(v \mid P)}{\partial \theta}+M_{2}
$$

The right hand sides of (14) and (15) decompose the effects of a liquidity and information shock on prices into two components. The first component is the price change that occurs because the shock changes $\mathrm{E}(v \mid P)$. We refer to this as the "expectations component" of the price change because it measures that part of the price change which is due to revisions in the expectations of uninformed investors. We refer to the second component of the price change as the "portfolio balance component" because it measures how prices would respond to the shift in the excess demand curve for assets caused by the shocks if the uninformed investors believed that the shocks contained no information. It is important to emphasize that the expressions in equations (14) and (15) are matrices which summarize the sensitivity of prices to the shocks. Because prices are a linear function of the shocks (see appendix A) the total price response to a shock is the price sensitivity multiplied by the shock. For example, if there are more than three markets, then market 3's total price sensitivity to a liquidity shock in market 1 is the row 3, column 1 element of $\partial P / \partial \epsilon$; and the expectations and portfolio balance components of the total sensitivity are the $[3,1]$ elements of $M_{1} \partial \mathrm{E}(v \mid P) / \partial \epsilon$ and 
$M_{3}$, respectively. The relative importance of these components will be discussed shortly.

Before studying these components, it is useful to establish the general conditions for the existence of contagion. An immediate implication of our definition of contagion (as shocks in one market affecting prices in other markets) is that contagion cannot occur if $\partial P / \partial \epsilon$ and $\partial P / \partial \theta$ are both diagonal matrices. Whether or not there is contagion, and the relative importance of the expectations and portfolio balance components, depends on the numbers of informed and uninformed investors and on other elements of the economic environment.

\section{A Contagion and The Number of Informed and Uninformed In- vestors}

To understand the role that the number of informed and uninformed investors have for contagion it is useful to consider some limiting cases of our model. For the first limiting case we hold the number of uninformed investors fixed, but let the number of informed investors approach infinity. The result is that informed investors push asset prices toward their expected liquidation values in all markets, and hence there is no contagion. The economic intuition for this case is provided by the first order condition for informed investors' optimal portfolio choices. The first order condition requires risky assets to be priced so that, conditional on the informed investors' information, the assets earn the riskless rate of return plus a premium to compensate the investors for risk. Because the riskless rate is normalized to 0 , the first order condition requires risky asset prices to equal the expected value of $v$ conditional on their information, $\theta$, plus a risk premium. As the number of informed investors approaches infinity, the amount of risky asset each holds goes to 0; this forces the equilibrium risk premium to 0 and causes $P$ to converge to $\theta$. Using this limiting expression for $P$, one can see that $\partial P / \partial \theta=I$ and $\partial P / \partial \epsilon=0$. Since both of these are diagonal there is no contagion. In our simulation results (section III.B) we find that when more than $5 \%$ of the investors are informed, they drive prices towards fundamentals in all markets, and the

amount of contagion becomes small. Gennotte and Leland (1990) and Admati (1985) also 
find that when there is more than a small proportion of informed investors, prices closely reflect fundamentals.

The second limiting case holds the number of uninformed investors fixed and allows the number of informed investors to approach 0 . As the number of informed investors goes to 0 , prices only convey public information. This occurs because $\mathrm{E}(v \mid P)$ converges to its expected unconditional value, $\bar{\theta}$. Since this unconditional expected value does not depend on $\theta$ or $\epsilon$, shocks do not affect expected asset values, and hence the entire price effect of shocks occurs through the portfolio balance component.

The third limiting case holds the number of informed investors fixed, but lets the number of uninformed investors approach infinity. The result is that the risk premium that uninformed investors earn for holding the risky assets goes to zero, and hence prices converge to $\mathrm{E}(v \mid P)$, the expected liquidation value of the assets conditional on the uninformed investors' information. In this limiting case, the price effect of shocks occurs only through the expectations component.

The second and third limiting cases are of particular interest because both approximate the realistic situation that the fraction of informed investors is small, but they reach opposite conclusions about the relative size of the portfolio balance and expectations components of price changes. This shows that the fraction of informed investors alone does not restrict the relative importance of the two components. Other elements of the economic environment, however, do affect their relative importance. We will return to this topic in section III.B below, after examining the role of the economic environment in determining the channels for contagion.

\section{B The Economic Environment and the Channels for Contagion}

In this subsection, to identify the channels for contagion, we first establish a set of conditions which are sufficient to ensure that there is no contagion between any markets. 
Proposition 2 If $\Sigma_{\theta}, \Sigma_{u}$, and $\Sigma_{\epsilon}$ are all diagonal matrices, then there is no contagion from any market to any other market.

Proof: See the appendix.

The intuition behind proposition 2 is that the conditions of the proposition rule out all channels through which a change in price in one market can have an effect on asset demands in another market. There are three general ways in which changes in price in one market can affect demand in other markets. The first two are the standard income and substitution effects from the Slutsky equation. The third is an information effect in which price changes in one market potentially reveal information about asset values in other markets.

Income effects are never present in our model due to our assumption that investors have CARA utility and are unrestricted in their ability to borrow. An additional consequence of our CARA utility assumption, combined with our assumption that liquidation values are normally distributed, is that risky assets are substitutes for each other only if their liquidation values are correlated. Proposition 2 restricts $\Sigma_{\theta}$ and $\Sigma_{u}$ to be diagonal, which forces liquidation values to be uncorrelated and hence rules out substitution effects.

Information effects in the model can occur in two ways. The first is if the informed traders' information is correlated across markets. If it is, then price changes in one market may be perceived as revealing information which is correlated with asset values in other markets. The second way information effects can occur is if noise trading is correlated across markets. If it is, then price changes in one market will affect uninformed investors' assessment of whether price changes in other markets are due to informed investors' information in those markets or due to noise. As a consequence, when there is correlated noise trading, a price change in one market will cause uninformed investors to alter their demands for assets in other markets. Our assumptions that $\Sigma_{\theta}$ and $\Sigma_{\epsilon}$ are diagonal rule out both of the ways that information effects can occur in the model.

To summarize, proposition 2 shows that when income, substitution, and information effects are ruled out in all markets then there is no contagion between those markets. A 
generalization of this result holds for groups (or blocks) of markets. If markets are grouped in a way such that the assets in each group are not substitutes for the assets in other groups, and if the price changes for the markets in each group reveal no information about asset values for markets in other groups, then there can be contagion among the markets within a particular group, but there cannot be contagion between the markets in different groups. The condition guaranteeing that there is no contagion across groups requires that the matrices $\Sigma_{\theta}, \Sigma_{u}$, and $\Sigma_{\epsilon}$ are conformably block diagonal. This result is stated formally in the next proposition:

Proposition 3 If one of the matrices $\Sigma_{\theta}, \Sigma_{u}$, or $\Sigma_{\epsilon}$ is block diagonal, and the other two matrices are conformably block diagonal with it, then there is contagion between the markets within a particular block but no contagion between markets in different blocks. ${ }^{6}$

Proof: See the appendix.

To study the channels for contagion in more detail, it is necessary to relax the conditions in proposition 2. When the conditions are relaxed, our model allows for contagion through three different channels. ${ }^{7}$ If $\Sigma_{\theta}$ is non-diagonal, then information on assets is correlated across markets. Recall that this is the channel for contagion explored in King and Wadhwani (1990). If $\Sigma_{\epsilon}$ is allowed to be non-diagonal, then a liquidity shock in one market is correlated with liquidity shocks in other markets. This is the channel for contagion considered in Calvo (1999). The third channel for contagion is cross-market rebalancing in which investors respond to a shock in one market by rebalancing their portfolios across markets. In our model contagion occurs through cross-market rebalancing if $\Sigma_{u}$ or $\operatorname{Var}(v \mid P)$ or both are

\footnotetext{
${ }^{6} \mathrm{~A}$ matrix is block diagonal if it can be represented as a partitioned matrix for which all elements of the off-diagonal submatrices are zero. Two matrices are conformably block diagonal if the first is block diagonal, and the second, when partitioned at the same rows and columns as the first, is also block diagonal.

${ }^{7}$ In a previous version, we included the demands of positive feedback traders whose net asset demands depended on lagged price changes in one or more markets, and showed that cross-market feedback trading provided an additional channel for contagion. We also found that if some market participants follow positive feedback strategies, possibly in the form of dynamic hedging, in one market (as in Gennotte and Leland (1990)), while other participants underestimate the extent of their activity, then the positive feedback trading may substantially exacerbate volatility in the market where it occurs, and through our contagion channels may exacerbate volatility in other markets as well.
} 
non-diagonal since under these conditions a price change in one market causes a change in asset demands in other markets. ${ }^{8}$

Although our model is useful for exploring contagion through a number of channels, in the remaining sections of our paper we focus exclusively on contagion through cross-market rebalancing. There are several reasons for this choice. First, the correlated information and correlated liquidity shock channels have already been considered in the literature - and neither appears capable of fully explaining important features of the cross-sectional pattern of contagion. Second, we can relate the cross-market rebalancing channel to the underlying economic and financial structure of the economy. To the extent these structures vary across time and countries, our model, when viewed in this context, has the potential to explain both the cross-sectional and time-series pattern of contagion.

\section{Contagion Through Cross-Market Rebalancing}

In this section and throughout the rest of the paper we restrict the model so that contagion only occurs through cross-market rebalancing. In the following two subsections, we show how the parameters of our model can be related to the underlying macroeconomic structure of the global economy; and we provide a stylized example that illustrates how the economic structure influences the pattern of contagion.

\section{A The Economic Structure of the Multiple Asset Model}

In this subsection, we slightly alter the interpretation of the risky assets by assuming that each of the $N$ risky assets in our model correspond to an individual country's entire asset market. With this interpretation the portfolio which consists of all of the risky securities in a country's markets is treated as that country's sole risky asset. When we refer to contagion,

\footnotetext{
${ }^{8}$ Recall from (4) and (6) that the demands of the informed and uninformed investors are $X_{I}(P, \theta)=\tau \Sigma_{u}^{-1}(\theta-P)$, and $X_{U I}(P)=\tau \operatorname{Var}(v \mid P)^{-1}(\mathrm{E}(v \mid P)-P)$. Differentiating these expressions with respect to $P$ while holding $\mathrm{E}(v \mid P)$ fixed shows that when $\Sigma_{u}$ or $\operatorname{Var}(v \mid P)$ is non-diagonal, then changes in the price of one asset cause changes in the demand for other assets.
} 
we thus now refer to the transmission of shocks across countries rather than across markets. As before, the liquidation value of the risky assets is denoted $v$. The vector $v$ can be decomposed into a component $\theta$ which represents the information of informed investors, and into a component $u$ which informed investors cannot explain:

$$
v=\theta+u \text {. }
$$

As explained above, we restrict the model so that contagion can only occur through cross-market rebalancing. Contagion through correlated liquidity shocks and correlated information is ruled out by requiring that $\Sigma_{\epsilon}$ and $\Sigma_{\theta}$ are diagonal. Constraining $\Sigma_{\theta}$ to be diagonal is equivalent to assuming that informed investors' information about the assets in country $i$ cannot be used to forecast the value of the assets in country $j$.

Our principal innovation is the structure that we place on $u$, that component of liquidation values about which both informed and uninformed investors are uncertain. To generate contagion through cross-market rebalancing we assume that $\Sigma_{u}$ is non-diagonal. This is equivalent to assuming that $u$ has a linear factor structure:

$$
u=B f+\eta,
$$

where $f$ is an $M \times 1$ vector of common factors which affect asset values in more than one country; $B$ is an $N \times M$ matrix of factor loadings, which represent the sensitivities of assets' liquidation values to $f$, and $\eta$ is an $N \times 1$ vector of country-specific factors. To remain consistent with our distributional assumptions from section I, we assume that the elements of $f$ are independently distributed and standard normal. We also assume that $f$ and $\eta$ are independent, and that the elements of $\eta$ are independently normally distributed with mean 0 and variance $\Sigma_{\eta}$.

Although the common factors $f$ and the idiosyncratic factors $\eta$ could have other interpre- 
tations, we consider them as representative of the macroeconomic determinants of countries' long run (period 2) asset values. In this view, equation (16) summarizes the macroeconomic risk factor structure of asset values for the global economy. The common factors $f$, because they affect asset values in more than one country, proxy for systematic macroeconomic risks such as global or regional business cycles (i.e. global or regional trends in GDP), changes in global discount factors, or in the terms of trade, or changes in the price of vital inputs such as oil. The country-specific factors embody differences in the fiscal, monetary, and regulatory policies that are pursued by each country.

Under our interpretation, investors' uncertainty about future asset values comes from their uncertainty about the future macroeconomic state as measured by the realizations of the macroeconomic factors. Although investors are uncertain about the realizations of the macroeconomic factors, we assume that investors know the macroeconomic risk-factor structure of long-run asset values. By this we mean they know which macroeconomic factors affect asset values $(f$ and $\eta$ ), they know their distributions, and they know how the factors affect asset values in all countries, i.e. they know $B$. This is equivalent to our earlier assumption (section I) that investors don't know $u$, but know its distribution.

Investors at time 1 will optimally choose their portfolios based on the information structure, and on their knowledge of the risk factor structure of assets' liquidation values. The information and risk factor structures together shape the pattern of contagion.

\section{B Contagion in a Three-Country Example}

The purpose of this subsection is to illustrate contagion through cross-market rebalancing in the context of a stylized example. In the example, there are three countries and two shared risk factors. Recall that each country is assumed to have only a single risky asset which consists of the market index for that country. The liquidation values of the assets take the 
form:

$$
\begin{aligned}
& v_{1}=\theta_{1}+\beta_{1} f_{1}+\eta_{1}, \\
& v_{2}=.5 f_{1}+.5 f_{2}, \\
& v_{3}=\theta_{3}+\beta_{3} f_{2}+\eta_{3},
\end{aligned}
$$

where the shared factors are $f_{1}$ and $f_{2}$, and for $i=1,2$, and 3, country $i$ 's liquidation value, country-specific private information, and country-specific macroeconomic risk are represented by $v_{i}, \theta_{i}$, and $\eta_{i}$ respectively.

The most important feature of the example is that countries 1 and 3 do not share any common macroeconomic factors; instead the assets in countries 1 and 2 share an exposure to risk factor $f_{1}$, and the assets in countries 2 and 3 share an exposure to risk factor $f_{2}$. We have constructed the example in this way in order to illustrate how a shock in country 1's asset market can spread to country 3 even though the liquidation value of the assets in countries 1 and 3 are determined by different macroeconomic risk factors. Our example is "extreme" in the sense that countries 1 and 3 share no common macroeconomic factors and, because private information is country-specific, the liquidation value of the assets in countries 1 and 3 are independently distributed.

In the example, country 2 acts as a conduit for transmitting shocks between countries 1 and 3. To focus on country 2's role, we at first assume that there are no information and liquidity shocks in country 2. Thus, country 2 has no information asymmetry and no liquidity traders. In addition, country 2 does not have a country-specific risk factor. Later we discuss how relaxing these assumptions affects the analysis.

To illustrate contagion, we solve the example for a baseline case and then examine how shocks in country 1 affect prices in all three countries. The baseline values of the parameters were chosen to maintain parsimony: $\beta_{1}$ and $\beta_{3}$, and the supply of risky assets are set equal to 1 ; and the random variables $f_{1}, f_{2}, \eta_{1}, \eta_{3}, \theta_{1}$, and $\theta_{3}$, and the demands of noise traders in 
countries 1 and 3 are distributed normally and independently with mean 0 and variance $1 .{ }^{9}$ Our choices of the numbers of informed and uninformed investors, and their risk tolerance $\left(\mu_{I}, \mu_{U I}\right.$, and $\left.\tau\right)$ deserves additional comment. Close examination of the expression for prices in our model (equations (13) and (20) through (24) in appendix A), shows that $\mu_{I}$ and $\mu_{U I}$ always appear multiplied by $\tau$. This means that the number of investors and their risk tolerances are not separately identified in the model. For simplicity, we have normalized investors' risk tolerances, $\tau$, to 1 . We have also chosen to set $\mu_{I}$ and $\mu_{U I}$ to 1 and 100 respectively. With this parameterization, $1 \%$ of the investors in the model are informed. ${ }^{10}$

Intuition for contagion in the baseline set-up can be provided by tracing through the effects that a perturbation to a shock in country 1 has on orderflow and prices in all three countries. For example, suppose that the markets in all three countries are in equilibrium in period 1 and then informed investors receive additional information which causes them to lower their assessment of country 1 's asset liquidation value by an amount $\mathrm{d} \theta_{1}$, (a negative information shock). Informed investors' optimal response to the new information is to sell some of country 1's assets. However, this lowers their exposure to risk factor $f_{1}$ below its optimal level. As a result, the informed investors adjust their exposure to $f_{1}$ by buying the assets of country 2 , but this raises their exposure to risk factor $f_{2}$ above its optimal level. The exposure to risk factor $f_{2}$ is adjusted by selling assets in country 3 thus completing the chain of contagion from country 1 to country 3 through country 2 . The direction of the resulting set of price changes is in accord with intuition: informed sales in the markets of countries 1 and 3 depress prices in those countries while raising prices in country 2 (Table I, panel A).

A negative liquidity shock in country 1 is transmitted to country 3 in a similar manner. When noise traders change their orderflow by selling an amount $\mathrm{d} \epsilon_{1}$ in country 1 , it will

\footnotetext{
${ }^{9}$ All of our results on the response of asset prices to shocks are invariant to the total supply of assets outstanding because the supply of assets affects the level of prices, but not how prices respond to shocks.

${ }^{10} \mathrm{~A}$ single investor with a high tolerance for risk generates the same demand as 100 investors whose risk tolerances are 100 times smaller. Because the risk tolerance parameter and the number of investors are not separately identified, the number of informed and uninformed investors should not be taken literally: they instead represent the amounts of informed and uninformed trading in the market.
} 
depress prices in country 1 , inducing informed traders to absorb some (but not all) of the noise trader sales. These purchases increase informed investors exposure to $f_{1}$ above its optimal level. The informed investors adjust their exposure to $f_{1}$ by selling in country 2 ; but this decreases their exposure to $f_{2}$ below its optimal level. To increase their risk exposure to $f_{2}$, they then buy in country 3 . The result is that prices decline in countries 1 and 2 while rising in country 3 (Table I, panel B).

One measure of the magnitude of contagion in the example is the amount of price variation in countries 2 and 3 that occurs because of shocks from country 1 . When measured as a proportion of variance, shocks from country 1 account for $50 \%\left(=2.45 \times 10^{-5} / 4.90 \times 10^{-5}\right)$ of the variance of prices in market 2 , and $32 \%(=0.1961 / 0.6115)$ of the variance of prices in market 3 (Table I, panel C). Although the shocks have large effects as a proportion of variance in all three countries, the size of the price changes, as measured by the variance of price, is much larger in countries 1 and 3 than in country 2. The reason for the difference is that informed investors have private information about liquidation values in countries 1 and 3 , but not in country 2. Because of the information asymmetry, uninformed investors rationally believe that orderflow in each of countries 1 and 3 might be due to private information about asset values in that market. As a result, orderflow in countries 1 and 3 alters uninformed investors' expectations of asset values, and hence prices. In the example, changes in expectations explain the vast majority of the price changes in countries 1 and 3 (Table I, panels A and B). By contrast, the orderflow has only a small effect on prices in country 2 because there are no information asymmetries there. ${ }^{11}$

The relatively large price responses induced by asymmetric information provide one of the primary insights of the model. If emerging markets have more information asymmetry than

\footnotetext{
11 Because there are no information asymmetries in country 2, it is at first surprising to find that price changes in country 2 have any expectational component. To see why, recall from equation (14) that the expectational component of the price change due to an information shock in country 1 is $M_{1} \partial \mathrm{E}(v \mid P) / \partial \theta_{1}$, where in this case $M_{1}$ is a $3 \times 3$ matrix. Although the shock has no effect on expectations about asset values in country 2 , if $M_{1}[2,1]$ and $M_{1}[2,3]$ are nonzero, then the effect of the shock on expected liquidation values of assets in countries 1 and 3 will have a price effect in country 2 . Table 1 shows the expectations component of the price change in country 2 is small.
} 
developed markets because public information on the value of assets in emerging markets is less readily available, then our three-country example helps to explain the cross-sectional differences in the pattern of contagion among emerging and developed markets. ${ }^{12}$ More specifically, if countries 1 and 3 are viewed as emerging markets, and country 2 is viewed as a developed market because its information asymmetries are low, then the example shows it is possible for large price shocks to be transmitted from one set of emerging markets to another through developed markets without significantly affecting prices in developed markets. This may explain why emerging markets appear to have been particularly vulnerable to contagion while developed markets have remained relatively unscathed.

When we allow a more general setting in country 2's asset markets the pattern of contagion between countries 1 and 3 is qualitatively similar, but conditions in country 2 have interesting quantitative effects on the magnitude of price movements. In this regard, it is important to note the role that information asymmetry in country 2 plays in the transmission of shocks. If there is more information asymmetry in country 2 , then its asset prices will be more sensitive to orderflow. This raises the cost of rebalancing risk exposures in country 2's market. As a result, there will be less cross-market rebalancing from country 1 to country 2 , and less rebalancing from country 2 to country 3, reducing country 3's price response to shocks from market $1 .{ }^{13}$ Because this example shows that more information asymmetry in developed markets reduces contagion among emerging markets, it suggests that steps which

\footnotetext{
${ }^{12}$ Evidence for asymmetric information in emerging markets is suggested by the results of Claessens, Djankov, and Lang (2000) who studied the ownership and control structure of publicly traded companies in nine South East Asian countries. In eight of the nine countries (Japan was the exception) they found between one-third and one-half of market capitalization are effectively controlled by the members of 15 families. Members of such families are likely to have better information than other investors regarding a related companies' prospects. The results of Frankel and Schmukler (1996), Froot, et. al (1998), Brennan and Cao (1997), and Seasholes (1999) also indirectly show that domestic and foreign investors may be differentially informed, although the papers reach different conclusions on whether foreign or domestic investors have the better information.

${ }^{13}$ In equilibrium informed investors' demands for assets in country 2 contain two components: the first component is associated with hedging factor risk, and the second is "speculative" reflecting differences between market prices and the assets' liquidation value. When there is asymmetric information in country 2 , informed investors' purchases drive up prices in country 2, inducing less speculative demand for assets in country 2. Because the speculative and hedging components are partially offsetting, the net amount of cross-market rebalancing declines.
} 
reduce information asymmetries in developed markets may have the unintended consequence of enhancing developed markets' role as a conduit for contagion among emerging markets.

Additionally, the importance of country-specific factors in determining liquidation values in developed markets plays a role in determining the magnitude of contagion. When the liquidation value of assets in country 2 is more dependent on country-specific factors, (i.e. when the variance of $\eta_{2}$ is larger), then more basis risk is incurred when investors use country 2 to rebalance their exposures to the common risk factors $\left(f_{1}\right.$ and $\left.f_{2}\right)$. As a result, investors incentive to rebalance across countries is reduced as are the price effects from a shock in country 1 on prices in other countries. More noise trading in country 2 also tends to reduce the effect that shocks in country 1 have on country 3, but for a different reason. When there is noise trading in country 2 , informed investors will take the other side and then rebalance their positions in countries 1 and 3. Because this increases the relative likelihood that trading in countries 1 and 3 is due to cross-market rebalancing, and not due to private information about the asset values in countries 1 and 3, this tends to reduce the informational content of the orderflow, and hence reduces the expectational component of the price response to orderflow in countries 1 and 3 .

The most important insight from our example is that it shows how contagion can occur between the markets of countries 1 and 3 even when channels of contagion such as correlated information, correlated liquidity shocks, and wealth effects are ruled out by assumption, and even when the liquidation value of the assets in countries 1 and 3 have no macroeconomic risk factors in common, and are in fact statistically independently distributed. This means our model provides a possible explanation for the contagion that has been observed between countries with different macroeconomic fundamentals. For example, our model may explain how financial market contagion could have spread from Mexico to Asia during the Mexican crisis in 1994, and from Asia to Latin America during the 1997-98 Asian crisis. It may also provide insight into the transmission of market turbulence to Latin American following the 1998 Russian default. 
Frankel and Schmukler's (1998) study of closed-end country funds provides some support for the transmission mechanism in our model. They showed that contagion could have spread from Mexico through New York to Asia in the aftermath of the Mexican peso devaluation in December 1994. Using Granger-causality tests, they examined the timing of price movements of closed-end country funds and their net asset values (NAVs). During the Mexican crisis they found that NAVs of Mexican funds declined before the devaluation, while the price of Mexican closed end funds trading in New York did not decline until after the devaluation occurred. The declines in the closed end fund prices then Granger-caused falls in funds representing Asian stocks. Frankel and Schmukler interpreted their evidence as suggesting that some investors were differentially informed and that, in this case, local investors in Mexico lost confidence before investors in New York. They also found that the transmission of shocks among emerging markets may occur indirectly through a third country.

Our main results in this section can be summarized as follows:

- Contagion can occur between countries whose long-run asset values are driven by different macroeconomic fundamentals, provided they are linked by sharing common macroeconomic fundamentals with a third country or countries.

- Differences in information asymmetries between developed and emerging markets may explain why emerging markets were hit hard by contagion while developed markets remained relatively unscathed.

- In some circumstances, higher quality markets (in the sense of less information asymmetry and less country-specific risk) in developed countries may worsen the contagion among emerging markets.

In the next section we use our three-country example to examine the role of the macroeconomic factors in contagion. 


\section{Contagion and Fundamentals}

An important focus of the policy debate on contagion centers around whether asset price movements in those countries which are hardest hit by contagion are excessive relative to that country's fundamentals. In this section, we address this question in two ways. First, we directly examine whether price movements are excessive relative to fundamentals. Then, we contrast the role that macroeconomic fundamentals play in determining the pattern of contagion in our model relative to more traditional models of contagion.

\section{A Are Price Movements Excessive Relative to Fundamentals?}

In the previous section we established that contagion exists between countries 1 and 3 when contagion is defined as a shock in one country's asset market that causes price movements in other countries' asset markets. In much of the literature, however, contagion is defined more narrowly as a shock in one country that generates price movements in other countries that are excessive relative to "full information" fundamentals. We can show that the price movements in our three country example meets this more restrictive definition.

The analysis here relies on our earlier decomposition of the effect of shocks on asset prices into an expectations component which measures that part of the price change that occurs because of a change in $\mathrm{E}(v \mid P)$, and into a portfolio balance component which measures that part of the price change that occurs because of the reallocation of risk-sharing among investors (equations (14) and (15)). To see how the decomposition is useful, recall that the liquidation value of the assets in countries 1 and 3 are statistically independently distributed. An implication of statistical independence is that conditional on full information, a shock which all participants know originates in country 1 cannot cause a reassessment of the expected liquidation value of the assets in country 3. Therefore any price change that occurs because a shock in country 1 altered $\mathrm{E}(v \mid P)$ in country 3 is excessive relative to full information fundamentals. 
To test for whether price movements in country 3 are excessive it suffices to examine the expectations component of the price change in country 3 due to a shock in country 1. In the current parameterization, the expectations component of the price changes is much larger than the portfolio balance component (Table I, Panels A and B). The relative size of these components is not our primary focus because it can vary for realistic values of the number of informed and uninformed investors (see section II.A). ${ }^{14}$ The important result is that shocks in country 1 change expectations about the value of country 3's assets. Because they do, price movements in country 3 due to a shock in country 1 are excessive relative to full information fundamentals.

A more conventional method for showing that price movements are excessive relative to full information fundamentals is to solve the model when all investors are informed and then contrast the resulting price movements with those from the baseline model. We followed this approach in an earlier version and reached the same conclusions.

\section{B Role of Macroeconomic Factors in Contagion}

A number of papers have explored the relationship between macroeconomic news and the cross-sectional pattern of contagion. The general finding in this literature is that macroeconomic news can account for only a small part of asset return covariation across countries at high frequencies. Our model provides one reason for the weak explanatory power.

Recall that in the model contagion occurs in period 1, but the macroeconomic risk factors $f_{1}$ and $f_{2}$ are not realized until time period 2. Moreover, before period 2 the investors receive neither public nor private information about the factors. An immediate consequence is that the realizations of the macroeconomic risk factors in period 2 do not influence the pattern

\footnotetext{
${ }^{14}$ In further simulations we found that for most values of $\mu_{I}$ and $\mu_{U I}$ the expectations component of the price changes is much larger than the portfolio balance component. The exception was when the numbers of both types of investors were much smaller than in our baseline model, or equivalently when investors were much more risk averse than in our baseline model.
} 
of contagion in period $1 .{ }^{15}$ This is consistent with the results that have been reported in recent studies. ${ }^{16}$

Although the realizations of the macroeconomic risk factors do not explain the pattern of contagion in our model, the risk factors are important, but not as used in prior models. Instead the risk factors are central because contagion is transmitted through investors' rebalancing their portfolio's exposures to the future risk factor realizations. Because contagion occurs through the reoptimizing of portfolio's risk exposures, it is the long-run macroeconomic risk factor structure which plays an essential role in determining the pattern of contagion. We turn to this topic in the next section when we examine how the pattern of contagion is influenced by assets' sensitivities to these systematic risk factors.

\section{Explaining the Severity of Contagion}

During each of the recent episodes of financial market contagion, the severity of the episodes varied across countries. Our model helps to identify several characteristics which make a country vulnerable to contagion. In this section we focus on how country 3 is affected by two of these characteristics, the exposure of its asset values to systematic macroeconomic risk factors, and the amount of information asymmetry within country 3. Results for how conditions in country 3 affect other countries' markets are available upon request.

\section{A Role of Sensitivities to Systematic Risk Factors}

In this subsection we will explore the role of an asset market's sensitivities to the systematic risk factors in generating contagion. Before analyzing this question in depth, it is useful to note that Proposition 3 implies that when a country's sensitivities (factor $\beta$ 's) to the

\footnotetext{
${ }^{15}$ It is important to emphasize that our model is designed to show that it is possible to generate contagion even in the absence of news about the macroeconomic risk factors. In a more realistic model in which news about the macroeconomic risk factors arrived in time period 1, it would obviously influence the pattern of contagion.

${ }^{16}$ See Kaminsky and Schmukler (1999), Baig and Goldfajn (1999), and Connolly and Wang (2000) as examples.
} 
common risk factors are zero, then in the cross-market rebalancing variant of our model there is no contagion to or from that country. The intuition for this result is that when a country's factor $\beta$ 's are zero, it shares no risk factors with other countries. Thus its markets cannot be used for rebalancing risk factor exposures. An immediate implication is that in the cross-market rebalancing variant of our model, contagion only occurs among countries that are directly or indirectly linked through the sharing of common macroeconomic risk factors.

To illustrate the role of shared risk factor exposures, we examine how country 3's price response to shocks in country 1 varies with $\beta_{3}$, country 3's exposure to risk factor $f_{2}$. Because the intuition for the sign of the price response was provided in section III.B, only the magnitude of the price response is discussed here.

The magnitude of country 3's price response to information and liquidity shocks from country 1 is a non-monotone function of $\beta_{3}$. When $\beta_{3}=0$, country 3 shares no risk factors with other countries, and hence its price response is zero. As $\beta_{3}$ increases from 0 , informed participants begin to use country 3's market to hedge against changes in $f_{2}$. This increase in hedging activity from 0 initially increases country 3's price response to shocks from country 1. However, as $\beta_{3}$ continues to grow, it becomes increasingly likely that orderflow in country 3 is due to cross-market rebalancing and not private information. ${ }^{17}$ As a result the magnitude of the price response in country 3 to shocks from country 1 eventually declines (Figures 1 and 2, panel C). ${ }^{18}$

\footnotetext{
${ }^{17}$ Higher $\beta_{3}$ reduces the relative amount of informed trading in market 3 because it increases the amount of cross-market rebalancing in country 3 , and it reduces the amount of trading based on market 3's private information. This latter effect occurs because higher $\beta_{3}$ increases the exposure to factor $2\left(f_{2}\right)$ risk that informed investors incur when trading on country 3's private information.

${ }^{18}$ When the assumption of no noise traders in country 2 is relaxed then noise trading in country 2 generates uninformative cross-market rebalancing trades in countries 1 and 3 . This increase in uninformative trading reduces the magnitude of the price response to both information and liquidity shocks emanating from country 1 (not shown), but the price responses are qualitatively similar. The exception being that price responses in country 3 to liquidity shocks from country 1 are significantly smaller and of the opposite sign as $\beta_{3}$ ranges from 0 to approximately 2.5 .
} 


\section{B Role of Information Asymmetry}

One measure of the amount of information asymmetry in each country is the amount of private information that informed investors have about its assets' liquidation value. This can be measured by the variance of $\theta$ in that country. In this subsection we examine how price sensitivities to shocks originating in country 1 in our baseline model depend on the amount of information asymmetry in country 3.

When there is no information asymmetry in country 3 , then shocks in country 1 have little effect on prices in country 3. As the amount of information asymmetry increases in country 3, the price response increases monotonically. This is our most important result because it shows that more information asymmetry in country 3 increases its vulnerability to contagion (Figures 3 and 4, panel C). Intuition for the result is that greater information asymmetries within a country's market increase the likelihood that shocks transmitted to that market from abroad will be mistakenly viewed as an information shock within that market, magnifying price changes.

\section{Summary}

Our principal results on the role of risk factor sensitivities and information asymmetries are restated below:

- Contagion occurs across countries whose asset values are linked through sharing exposures $(\beta)$ to common macroeconomic fundamentals. Increases in $\beta$ from zero increase a country's vulnerability to contagion.

- When $\beta$ is not equal to zero, changes in $\beta$ do not have a simple relationship to the pattern of contagion and can either increase or decrease a country's vulnerability to shocks from abroad.

- More information asymmetry within a country's asset market increases the magnitude of that market's price response to contagion from abroad. 


\section{Explaining the Pattern of Contagion Across Coun- tries and Through Time}

One shortcoming of the model is that it is static, and the parameters of the model are fixed. As a result, the model helps to explain the cross-country pattern of financial market contagion, but makes no predictions about how it changes through time. In particular, the model, considered alone, cannot explain why financial market contagion appears to be more acute during some time periods than others. One way to gain further insight into the dynamics of contagion is to treat the model's parameters as being formally determined by other elements of the economic environment. In particular, we consider how changes in some of these elements affect two determinants of a country's vulnerabilty to financial contagion: the sensitivity of a country's asset values to fluctuations in systematic macroeconomic factors, and the amount of information asymmetry within a country.

One important element that could cause time variation in the sensitivity of an asset market to the risk factors is a country's movement from a fixed to flexible exchange rate regime. A regime switch of this sort adds an important risk by increasing a country's asset market exposure to exchange rate fluctuations from zero, opening up the potential for contagion through cross-market rebalancing. An alternative explanation for time variation in risk factor sensitivities is the dramatic increase in financial leverage experienced by some companies during an exchange rate or financial crisis. For example, during the Asian financial crisis, exchange rate devaluations in some countries dramatically increased the market value of many companies' foreign-denominated debt obligations and dramatically reduced the market value of shareholders' equity, raising their debt-equity ratios. The increase in financial leverage increases factor sensitivities and can substantially alter the pattern of contagion.

Changes in informational asymmetries, as a result of the onset of banking and financial crises in some countries, may also help explain the time-series pattern of contagion in the context of our model. Although there are many ways asymmetric information could manifest 
itself, one type of informational advantage that some investors could have is superior knowledge of various companies' financial condition, and those companies' access to emergency sources of credit. It could also represent some investors' differential access to knowledge about government economic policy. For instance, Claessens, Djankov, and Lang (2000) note that the families which control large chunks of market capitalization in the countries in South East Asia often have close ties to government. When macroeconomic conditions are stable most companies will be in sound financial condition, and therefore knowledge of companies' access to emergency funding from public or private sources will have relatively little value. Therefore, in good times the degree of information asymmetry will be low. During financial or banking crises, the same type of information becomes very valuable in establishing prices for companies' equity. Consequently informational asymmetries, as measured by the value of what the better informed investors know, become larger. More generally, during financial and banking crises, anecdotal evidence suggests a great deal of confusion about the values of companies, lending credence to an increase in informational asymmetries during these periods.

The recent abrupt changes in exchange rate regimes from fixed to floating, and the increases in financial leverage experienced by many corporations in emerging markets during financial crises, increase parameters in our model which are linked to increased vulnerability to financial market contagion. We believe this provides some additional insight into why financial market contagion has increased recently, and how the pattern of financial market contagion might change through time.

\section{Conclusions}

In this paper we presented a multiple asset, noisy rational expectations model of asset prices and used the model to study the determinants of financial market contagion over short periods of time such as a day or a week. The model nests the correlated information and correlated liquidity shock channels for contagion considered by others and also contains a 
new channel which we refer to as cross-market rebalancing. Contagion occurs through this third channel when market participants are hit with an idiosyncratic shock in one country and transmit the shock abroad by optimally rebalancing their portfolio's exposures to macroeconomic risks through other countries' markets. Countries whose asset values are driven by common macroeconomic factors are vulnerable to this form of contagion, but it can also occur between two countries whose asset values are determined by independent macroeconomic factors, provided they are indirectly linked through third countries. Crossmarket rebalancing may thus explain contagion between Asia and Latin America during recent crises even though the macroeconomies of the two regions are only weakly linked.

One of our most important findings is that asymmetric information makes a country more vulnerable to contagion from abroad. Most of the contagious price response in a given country occurs because the order flow from cross-market rebalancing from other countries is partially misinterpreted as being related to information about asset values within that particular country. The model suggests that one possible protection against undesired, excessive price movements is a reduction in informational asymmetries through better transparency and more open access to information underlying the value of assets. The model also shows the rather perverse result that as informational asymmetries shrink in developed countries' markets, these countries act to transmit contagion among emerging market countries rather than contain it.

To close, it is useful to relate our paper to the contagion literature which stresses macroeconomic channels. Our theoretical model and this literature both are built upon the common notion that macroeconomic fundamentals are an important element of contagion, but we use these fundamental relations in a new way. Instead of looking to the realizations of macroeconomic fundamentals or macroeconomic news to rationalize the pattern of financial market contagion (an approach which appears to explain little empirically), we model long-run asset values across countries as depending on common macroeconomic factors and we model contagion as a consequence of the optimal rebalancing of exposures to macroeconomic risks. In 
this framework, contagion does not depend on macroeconomic news. Nor do macroeconomic fundamentals need to be realized for contagion to occur. Portfolio rebalancing within this framework, however, would be relatively benign if it were not for the presence of asymmetric information. Information asymmetries help to account for why asset price movements are far larger in some countries than can be justified by the movements of their macroeconomic fundamentals. One can also use the model to consider how some of the parameters change through time, providing additional insight into the timing of contagious episodes. Thus, by combining portfolio rebalancing and information asymmetries, our model identifies an additional channel for contagion that can formally explain why some countries are hit, and hit hard, by contagious episodes while others are not. 


\section{Appendix}

\section{A Equilibrium Beliefs, Prices, and the Variance of Prices}

In this section of the appendix we solve for equilibrium beliefs for the general model described in section I. The equilibrium beliefs are solved for by imposing the belief consistency conditions in equations (11) and (12) while exploiting the normality of $S(P), \theta$, and $\epsilon$. Using the right hand side of the expression for $S(P)$ (equation (9)) and the joint distribution of $\theta$ and $u$ (equation (2)), the equilibrium beliefs are:

$$
\begin{aligned}
\mathrm{E}(v \mid P) & =\mathrm{E}(v \mid S(P)) \\
& =\bar{v}+\operatorname{Cov}[S(P), v][\operatorname{Var}(S(P))]^{-1}[S(P)-\mathrm{E}\{S(P)\}] \\
& =\bar{\theta}+\Sigma_{\theta}\left[\Sigma_{\theta}+\frac{\Sigma_{u} \Sigma_{\epsilon} \Sigma_{u}}{\left(\tau \mu_{I}\right)^{2}}\right]^{-1}[S(P)-\bar{\theta}] \\
& =\bar{\theta}+\Sigma_{\theta}\left[\Sigma_{\theta}+\frac{\Sigma_{u} \Sigma_{\epsilon} \Sigma_{u}}{\left(\tau \mu_{I}\right)^{2}}\right]^{-1}\left[\theta+\frac{\Sigma_{u} \epsilon}{\tau \mu_{I}}-\bar{\theta}\right],
\end{aligned}
$$

and

$$
\begin{aligned}
\operatorname{Var}(v \mid P) & =\operatorname{Var}(v \mid S(P)) \\
& =\Sigma_{v}-\operatorname{Cov}(v, S(P))[\operatorname{Var}(S(P))]^{-1} \operatorname{Cov}(v, S(P))^{\prime} \\
& =\left[\Sigma_{\theta}+\Sigma_{u}\right]-\Sigma_{\theta}\left[\Sigma_{\theta}+\frac{\Sigma_{u} \Sigma_{\epsilon} \Sigma_{u}}{\left(\tau \mu_{I}\right)^{2}}\right]^{-1} \Sigma_{\theta}{ }^{\prime} .
\end{aligned}
$$

Equations (18) and (19) are not explicit functions of equilibrium price, but are instead consistency conditions on beliefs that must be satisfied by the equilibrium price function. ${ }^{19}$ Equilibrium prices are found by rewriting the market clearing condition (equation (8)) to solve for price $P$ as a function of the expressions for $\mathrm{E}(v \mid P)$ and $\operatorname{Var}(v \mid P)$ from equa-

\footnotetext{
${ }^{19}$ It is possible to solve for $\mathrm{E}(v \mid P)$ as an explicit function of $P$. The solution is:

$$
\mathrm{E}(v \mid P)=\phi_{0}+\phi_{1} \bar{v}+\phi_{2} P
$$
}


tions (18) and (19). Repeating from proposition 1, the rational expectations equilibrium price function $P$ for the model described by equations (1), (2),(4),(6), and (7) is

$$
P=M_{0}+M_{1} \mathrm{E}(v \mid P)+M_{2} \theta+M_{3} \epsilon
$$

where,

$$
\begin{aligned}
M_{0} & =-\Psi^{-1} X_{T} \\
M_{1} & =\Psi^{-1} \mu_{U I} \tau[\operatorname{Var}(v \mid P)]^{-1} \\
M_{2} & =\Psi^{-1} \mu_{I} \tau \Sigma_{u}^{-1} \\
M_{3} & =\Psi^{-1} \\
\Psi & =\mu_{U I} \tau[\operatorname{Var}(v \mid P)]^{-1}+\mu_{I} \tau \Sigma_{u}^{-1},
\end{aligned}
$$

and $\mathrm{E}(v \mid P)$ and $\operatorname{Var}(v \mid P)$ are given in equations (18) and (19).

Based on the expression for price, it follows that the unconditional variance of $\mathrm{P}$ is:

$$
\operatorname{Var}(P)=\Psi^{-1}\left(C \Sigma_{\theta} C^{\prime}+D \Sigma_{\epsilon} D^{\prime}\right) \Psi^{-1}
$$

where:

$$
\begin{aligned}
\phi & =\left[I+\operatorname{Cov}(S(P), v)[\operatorname{Var}(S(P))]^{-1} \frac{\left(1-\mu_{I}\right)}{\mu_{I}} \Sigma_{u} \operatorname{Var}(v \mid P)^{-1}\right] \\
\phi_{0} & =\phi^{-1}\left(\operatorname{Cov}(S(P), v)[\operatorname{Var}(S(P))]^{-1} \frac{\Sigma_{u}}{\left(\tau \mu_{I}\right)}\left[X_{T}\right]\right) \\
\phi_{1} & =\phi^{-1}\left(I-\operatorname{Cov}(S(P), v)[\operatorname{Var}(S(P))]^{-1}\right) \\
\phi_{2} & \left.=\phi^{-1}\left(\operatorname{Cov}(S(P), v)[\operatorname{Var}(S(P))]^{-1} \frac{\Sigma_{u}}{\tau \mu_{I}}\left[\mu_{U I} \tau[\operatorname{Var}(v \mid P)]^{-1}+\tau \mu_{I} \Sigma_{u}^{-1}\right)\right]\right)
\end{aligned}
$$

$\operatorname{Var}(v \mid P)$ cannot be written as a function of price because prices reveal no information on the variance of $v$ beyond that which is contained in knowledge of the structure of the model. 
where

$$
\begin{aligned}
C & =\mu_{U I} \tau[\operatorname{Var}(v \mid P)]^{-1} \Sigma_{\theta}\left[\Sigma_{\theta}+\frac{\Sigma_{u} \Sigma_{\epsilon} \Sigma_{u}}{\left(\tau \mu_{I}\right)^{2}}\right]^{-1}+\mu_{I} \tau \Sigma_{u}^{-1} \\
D & =\frac{C \Sigma_{u}}{\mu_{I} \tau}
\end{aligned}
$$

\section{B Proof of Propositions 2 and 3}

Proposition 2. If $\Sigma_{\theta}, \Sigma_{u}$, and $\Sigma_{\epsilon}$ are all diagonal matrices, then there is no contagion from any market to any other market.

Proof: Under the conditions of the proposition, inspection shows the derivatives of $\mathrm{E}(v \mid P)$ (equation (18)) with respect to $\epsilon$ and $\theta$ are diagonal matrices, as are $\operatorname{Var}(v \mid P)$ (equation (19)), $\Psi$ (equation (24)), and $\Sigma_{u}$. Their sums, products, and inverses are also diagonal. Therefore, evaluating equations (14) and (15) while using the expressions for $M_{1}, M_{2}$, and $M_{3}$ from equations (21), (22), and (23) shows that $\partial P / \partial \epsilon$ and $\partial P / \partial \theta$ are both diagonal matrices. Hence, there is no contagion.

Proposition 3. If one of the matrices $\Sigma_{\theta}, \Sigma_{u}$, or $\Sigma_{\epsilon}$ is block diagonal, and the other two matrices are conformably block diagonal with it, then there is contagion between the markets within a particular block but no contagion between markets in different blocks.

Proof: If for some common partition, the matrices $\Sigma_{\theta}, \Sigma_{u}$, and $\Sigma_{\epsilon}$ are conformably block diagonal, then their sums, products, and inverses are all conformably block diagonal with the same partition of the elements of the matrices. Because $\partial P / \partial \theta$ and $\partial P / \partial \epsilon$ involve only the sums products and inverses of these matrices, it then follows that $\partial P / \partial \theta$, and $\partial P / \partial \epsilon$ are block diagonal for the same common partition. Therefore, it follows that there is no contagion between assets (or markets) in different blocks. 


\section{BIBLIOGRAPHY}

Admati, Anat R., 1985, A noisy rational expectations equilibrium for multi-asset securities markets, Econometrica 53, 629-657.

Agénor, Pierre-Richard, and Joshua Aizenman, 1998, Contagion and volatility with imperfect credit markets, IMF Staff Papers 45, 207-235.

Allen, Franklin, and Douglas Gale, 2000, Financial contagion, Journal of Political Economy 108, 1-33.

Baig, Taimur, and Ilan Goldfajn, 1999, Financial markets contagion in the asian crises, IMF Staff Papers 46, 167-195.

Brennan, Michael J., and H. Henry Cao, 1997, International portfolio investment flows, Journal of Finance 52, 1851-1880.

Caballero, Ricardo, and Arvind Krishnamurthy, 1999, Emerging market crises: an asset markets perspective, IMF Working Paper No. 99/129, (International Monetary Fund, Washington, DC).

Calvo, Guillermo A., 1999, Contagion in emerging markets: when Wall Street is a carrier, Working paper, University of Maryland.

Chan-Lau, Jorge A., and Zhaohui Chen, 1998, Financial crisis and credit crunch as a result of inefficient financial intermediation - with reference to the asian financial crisis, IMF Working Paper No. 98/127, (International Monetary Fund, Washington DC).

Claessens, Stijn, Simeon Djankov, and Larry H.P. Lang, 2000, Separation of ownership and control in east asian countries, Journal of Financial Economics 158, 81-112.

Connolly, Robert A., and F. Albert Wang, 2000, On stock market return comovements: macroeconomic news, dispersion of beliefs, and contagion, Working paper, University of North Carolina and Rice University.

Corsetti, Giancarlo, Paolo Pesenti, and Nouriel Roubini, 1999, Paper tigers? A model of the asian crisis, European Economic Review 43, 1211-1236.

Fleming, Jeff, Chris Kirby, and Barbara Ostdiek, 1998, Information and volatility linkages in the stock, bond, and money markets, Journal of Financial Economics 49, 111-137.

Frankel, Jeffrey A., and Sergio L. Schmukler, 1998, Crises, contagion, and country funds: effects on east asia and latin america, in Reuven Glick, ed.: Managing Capital Flows and Exchange Rates: Perspectives from the Pacific Basin, (Cambridge University Press, Cambridge).

Frankel, Jeffrey A., and Sergio L. Schmukler, 1996, Country fund discounts and the mexican crisis of December 1994: did local residents turn pessimistic before international investors? Open Economies Review(Suppl. 1) 7, 551-34.

Froot, Kenneth A., Paul G.J. O’Connell, and Mark S. Seasholes, 1998, The portfolio flows of international investors: I, NBER Working Paper No. 6687, (Boston, MA).

Gennotte, Gerard, and Hayne Leland, 1990, Market liquidity, hedging, and crashes, American Economic Review 80, 999-1021. 
Goldfajn, Ilan, and Rodrigo O. Valdés, 1997, Capital flows and the twin crises: The role of liquidity, IMF Working Paper No. 97/87, (International Monetary Fund, Washington DC).

Grossman, Sanford J., and Joseph E. Stiglitz, 1980, On the impossibility of informationally efficient markets, American Economic Review 70, 393-408.

Kaminsky, Graciela L., and Carmen M. Reinhart, 2000, On crises, contagion, and confusion, Journal of International Economics 51, 145-168.

Kaminisky, Graciela L., and Serio L. Schmukler, 1999, What triggers market jitters? A chronicle of the asian crisis, Journal of International Money and Finance 18, 537-560.

King, Mervyn A., and Sushil Wadhwani, 1990, Transmission of volatility between stock markets, Review of Financial Studies 3, 5-33.

Kyle, Albert S., and Wei Xiong, 2001, Contagion as a wealth effect, Forthcoming Journal of Finance, Papers and Proceedings.

Lagunoff, Roger D., and Stacey L. Schreft, 2001, A model of financial fragility, Forthcoming Journal of Economic Theory.

Pritsker, Matt G., 1997, Liquidity risk and positive feedback, in The Measurement of Aggregate Market Risk (Bank for International Settlements, Basle).

Rigobon, Roberto, 1998, Informational speculative attacks: good news is no news, Working paper, Massachusetts Institute of Technology.

Schinasi, Garry J., and R. Todd Smith, 2000, Portfolio diversification, leverage, and financial contagion, IMF Staff Papers 47, 159-176.

Seasholes, Mark S., 1999, Smart foreign traders in emerging markets, Working paper, Harvard University Business School.

Van Rijckeghem, Caroline, and Beatrice Weder, 2000, Spillovers through banking centers: a panel data analysis, IMF Working Paper No. 00/88, (International Monetary Fund, Washington, DC).

Wang, Jiang, 1993, A model of intertemporal asset prices under asymmetric information, Review of Economic Studies 60, 249-282.

Wang, Jiang, 1994, A model of competitive stock trading volume, Journal of Political Economy 102, 127-168.

Yuan, Kathy, 2000, Asymmetric price movements and borrowing constraints: a rational expectations equilibrium model of crisis, contagion, and confusion, Ph.D. Dissertation, Massachesetts Institute of Technology.

Zhou, Chunsheng, 1998, Dynamic portfolio choice and asset pricing with differential information, Journal of Economic Dynamics and Control 22, 1027-51. 


\section{Table I: Price Response to Shocks from Market 1: Baseline Case}

\begin{tabular}{lccc} 
A. Negative Information Shock & & & \\
\hline & Market 1 & Market 2 & Market 3 \\
Expectations Component & -0.5937 & $1.67 \times 10^{-17}$ & -0.3964 \\
Portfolio Balance Component & -0.0119 & $3.04 \times 10^{-18}$ & 0.0020 \\
\hline Total & -0.6055 & $1.97 \times 10^{-17}$ & -0.3945
\end{tabular}

B. Negative Liquidity Shock

\begin{tabular}{lccc}
\hline & Market 1 & Market 2 & Market 3 \\
Expectations Component & -0.1972 & $5.55 \times 10^{-18}$ & 0.1972 \\
Portfolio Balance Component & -0.0237 & -0.0050 & 0.0039 \\
\hline Total & -0.2209 & -0.0050 & 0.2011 \\
& & & \\
C. Variance of Prices & & & \\
\hline & Market 1 & Market 2 & Market 3 \\
From Market 1 Shocks & 0.4155 & $2.4507 \times 10^{-5}$ & 0.1961 \\
From Market 3 Shocks & 0.1961 & $2.4507 \times 10^{-5}$ & 0.4155 \\
\hline Total & 0.6115 & $4.90 \times 10^{-5}$ & 0.6115
\end{tabular}

Notes: For the baseline three-country example presented in section III, the price of risky assets in all three countries are a linear function of the liquidity and information shocks that originate in country 1 . The linear sensitivities of prices to the shocks are presented in panels A and B. The price sensitivities are further decomposed into an expectations and portfolio balance component. The expectations component measures that part of the price sensitivity that is due to shocks causing revisions in investors' beliefs. The portfolio balance component measures that part of the price sensitivity which occurs because shocks lead to the reallocation of risky asset holdings among market participants. Panel $\mathrm{C}$ decomposes the variance of prices in each market into the variance which is due to shocks from market 1 and the variance which is due to shocks from market 3 . 
Figure 1: Price Response to Information Shocks from Country 1: Role of Systematic Risk Exposure in Country 3

\section{A. COUNTRY 1}

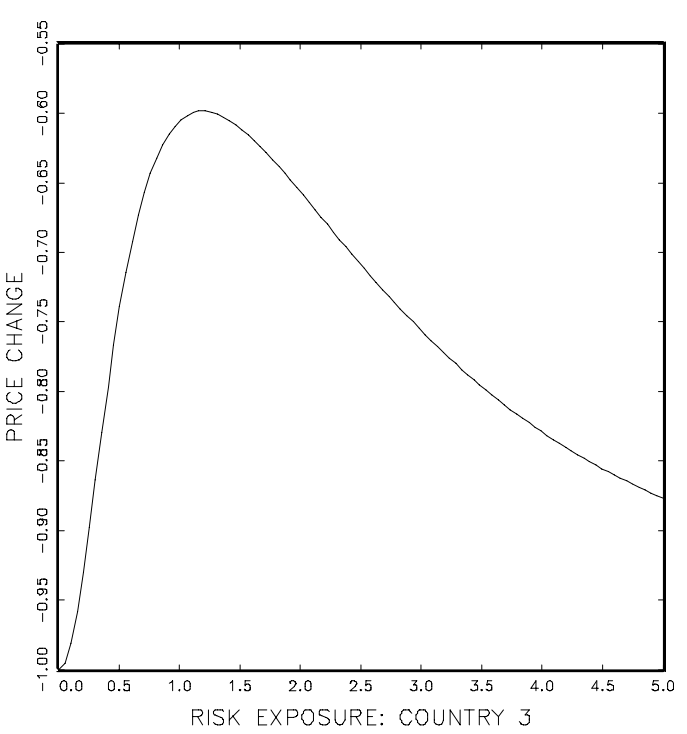

B. COUNTRY 2

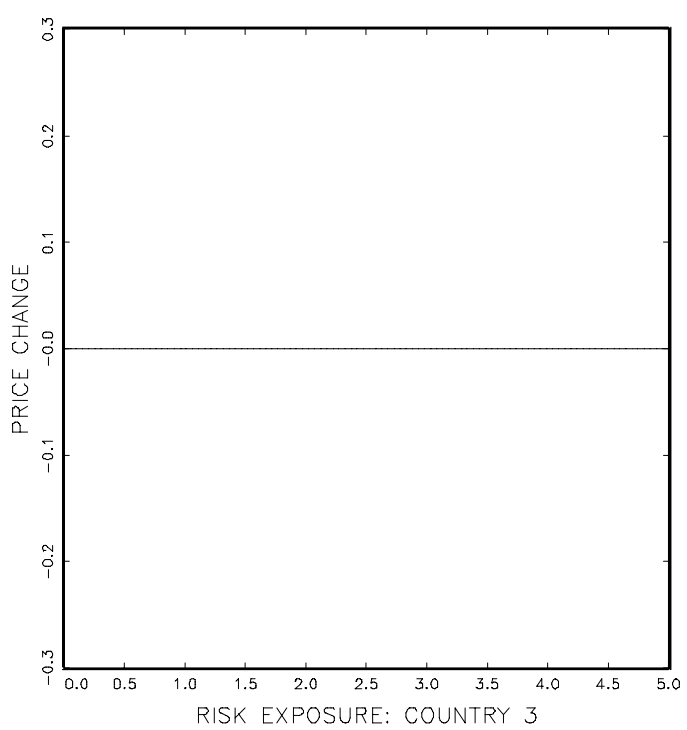

C. COUNTRY 3

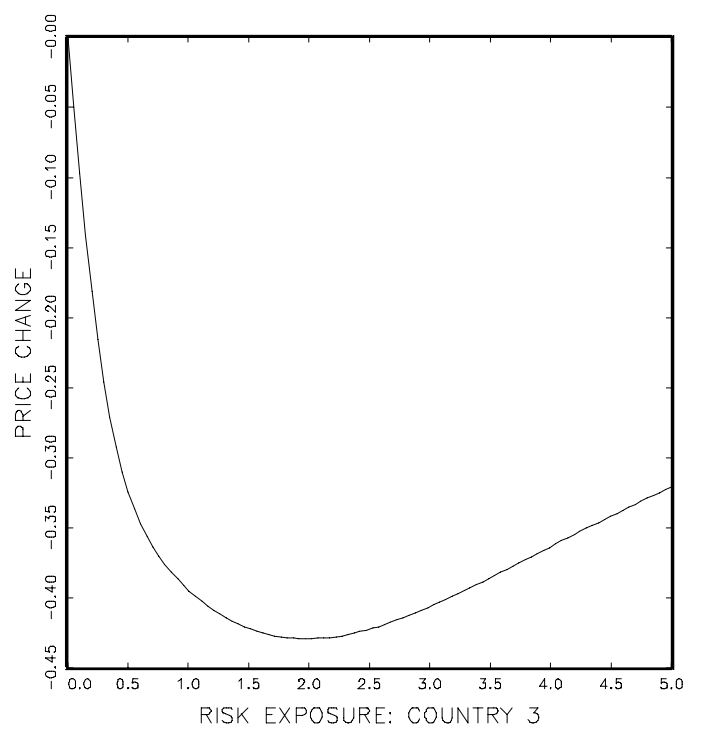

Notes: For the baseline three-country example presented in section III, the figure presents each country's price response to a one standard deviation negative information shock from country 1 as a function of the risk exposure of country 3's assets to macroeconomic risk factor $f_{2}$. Country 3's exposure to $f_{2}$ is denoted as $\beta_{3}$ in the text. 
Figure 2: Price Response to Liquidity Shocks from Country 1: Role of Systematic Risk Exposure in Country 3

A. COUNTRY 1

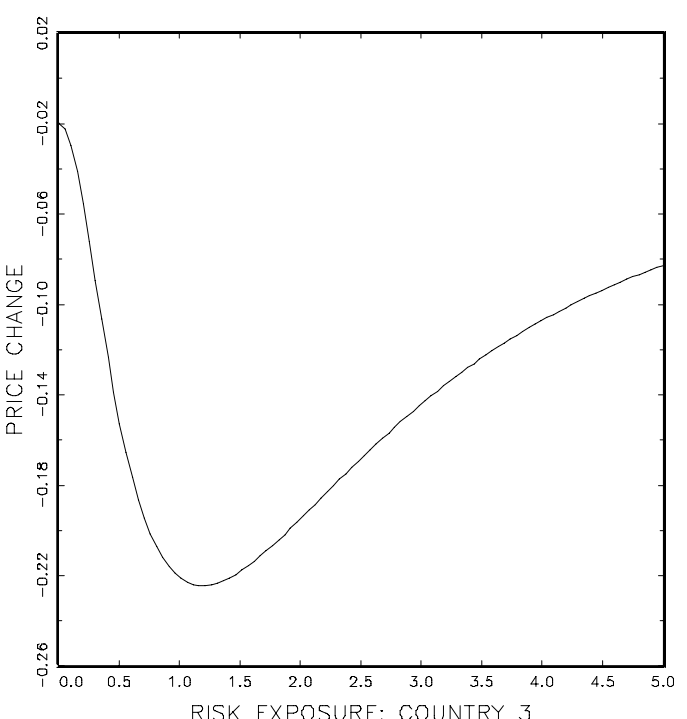

B. COUNTRY 2

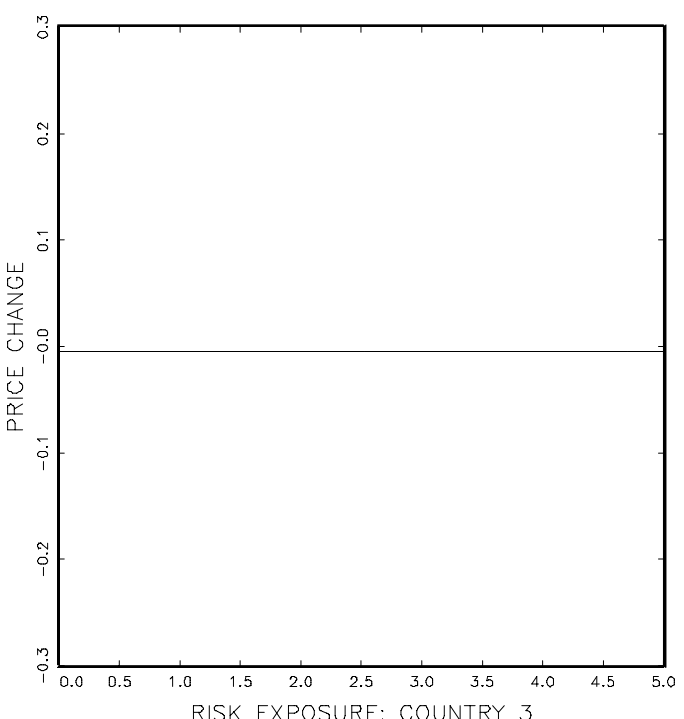

C. COUNTRY 3

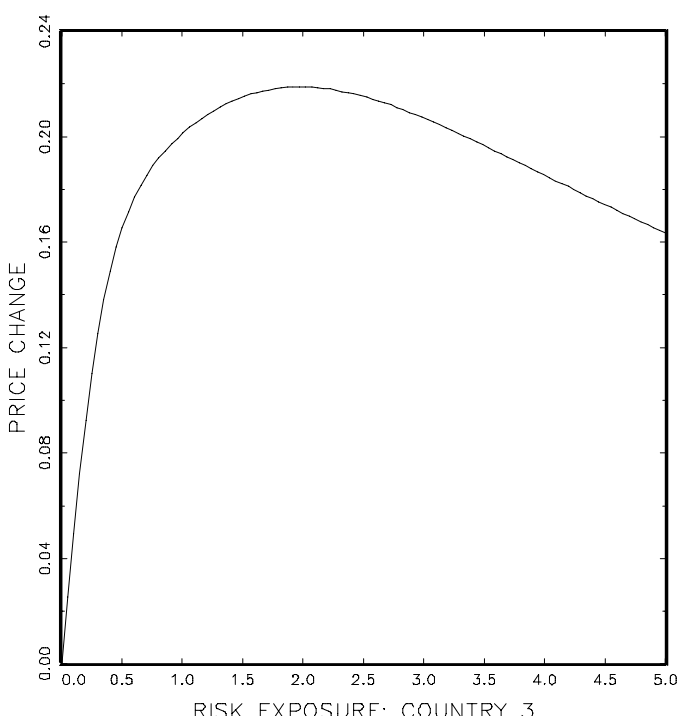

Notes: For the baseline three-country example presented in section III, the figure presents each country's price response to a one standard deviation negative liquidity shock from country 1 as a function of the risk exposure of country 3's assets to macroeconomic risk factor $f_{2}$. Country 3's exposure to $f_{2}$ is denoted as $\beta_{3}$ in the text. 


\section{Figure 3: Price Response to Information Shocks from Country 1: Role of Information Asymmetry in}

Country 3

\section{A. COUNTRY 1}

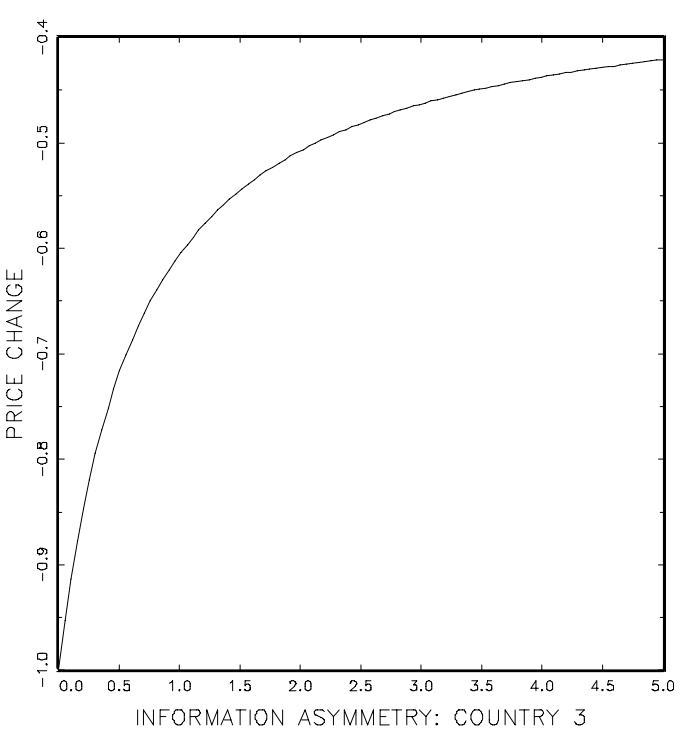

B. COUNTRY 2

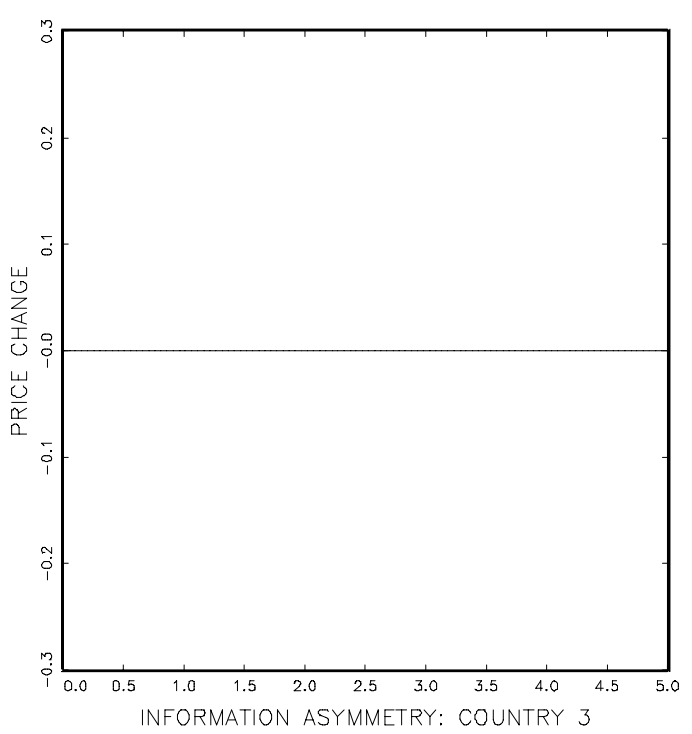

C. COUNTRY 3

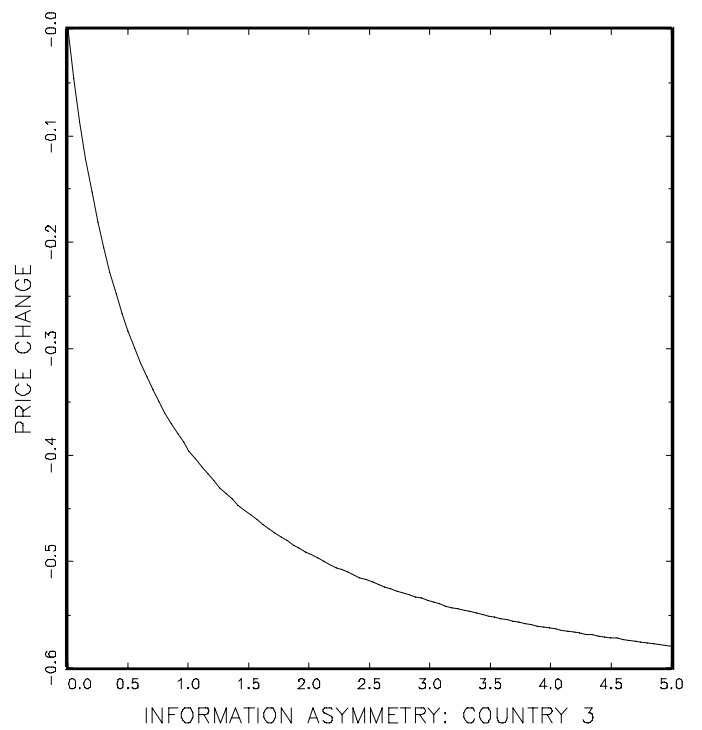

Notes: For the baseline three-country example presented in section III, the figure presents each country's price response to a one standard deviation negative information shock from country 1 as a function of the amount of information asymmetry in country 3 as measured by the amount of asset 3's value that can be explained by private information. This measure of information asymmetry is denoted by $\operatorname{Var}\left(\theta_{3}\right)$ in the text. 
Figure 4: Price Response to Liquidity Shocks from Country 1: Role of Information Asymmetry in Country 3

A. COUNTRY 1

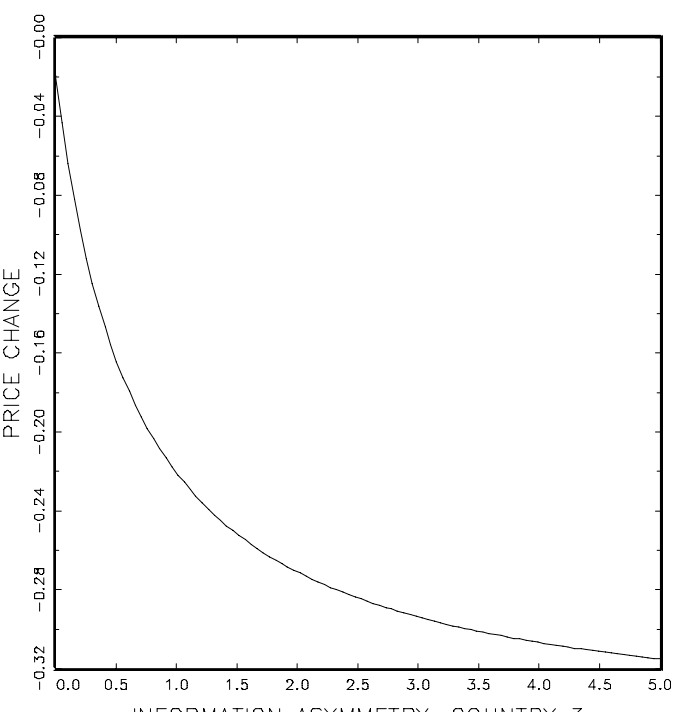

B. COUNTRY 2

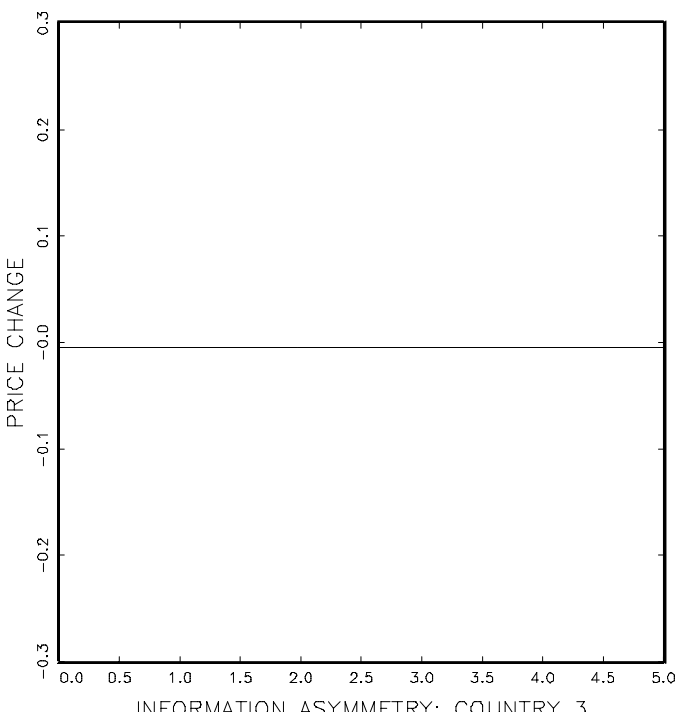

C. COUNTRY 3

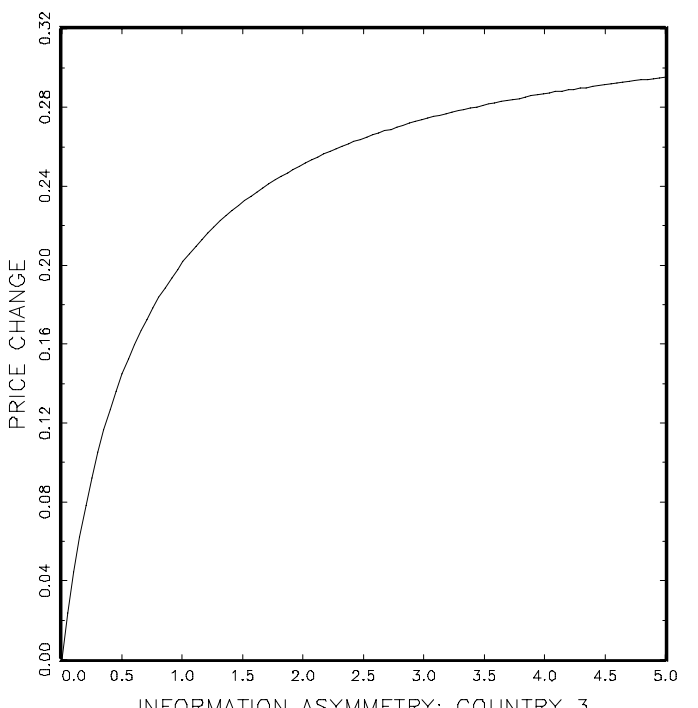

Notes: For the baseline three-country example presented in section III, the figure presents each country's price response to a one standard deviation negative liquidity shock from country 1 as a function of the amount of information asymmetry in country 3 as measured by the amount of asset 3's value that can be explained by private information. This measure of information asymmetry is denoted by $\operatorname{Var}\left(\theta_{3}\right)$ in the text. 